ancer. In: Hakama M, Miller AB, Day NE, eds Screening for cuncer of the ulerine cervix. Lvons: International Agency for Research on Cancer, 1985 161-8. (IARC Scientific Publications No 76.)

4 Chisholm D, Haran D. Cases of invasive cervical cancer in the north west in spite of screening. British fournal of Fumily Planning 1984;289:883-6.

Department of Health and Social Security. Cervical cancer screening. London DHSS, 1985. (DA $(85) 8$.)

6 Department of Health and Social Security. Health services management: cervical cancer screening. London: DHSS, 1988 (HC(88)1.)
7 Intercollegiate Working Party on Cervical Cytology Screening. Report. London: Royal College of Obstetricians and Gynaecologists, 1987.

8 Eardley A, Elkind A, Thompson R. HEA guidelines for a letter to invite women for a smear test: theory and practice. Health Education fournal 1990;49:51-6. 9 Pye M. NHS cervical screening programme: education and training needs of programme managers. Oxford: National Breast Cancer Screening Education Programme, 1989.

\title{
Management of major status epilepticus in adults
}

\author{
M D O'Brien
}

Major status epilepticus in adults is a medical emergency. The patient is often first seen in an accident and emergency department by a doctor who may not have had to deal with this problem before. The associated mortality is around $10 \%$, and convulsive seizures that last longer than two hours may be associated with permanent neurological sequelae. It is important to stop the seizures and then to keep the seizures under control. Seizure activity can nearly always be stopped, at least temporarily, with intravenous diazepam, but it should always be assumed that seizures are likely to start again, and the respite achieved with diazepam should be used to follow the protocol outlined below. Problems arise when these essential steps are not taken until after the fits resume.

(Accepted 13 fune 1990)

\section{Initial management}

(1) Remove any false teeth, establish an airway, and give oxygen by mask at a high flow rate. Assess the patient, verify the diagnosis, and place him or her in the lateral semiprone position.

(2) Diazepam (Diazemuls, $10 \mathrm{mg}$ in $2 \mathrm{ml}$ ) intravenously $0 \cdot 15-0 \cdot 25 \mathrm{mg} / \mathrm{kg}$, usually as a $10 \mathrm{mg}$ bolus followed immediately by a further $10 \mathrm{mg}$ $(2 \mathrm{ml}$ ) over 1-2 minutes. This may be repeated once if necessary. (See note 1.)

(3) Take blood ( $5 \mathrm{ml}$ in a fluoride tube) for measurement of anticonvulsant drugs, alcohol, and sugar concentrations; also measure concentrations of calcium, electrolytes, and urea, obtain a full blood picture, and put a drop of blood on to a test strip (BM stick). Save a blood sample for a drug screen.

(4) If the result on BM stick testing indicates a low blood glucose concentration give $50 \%$ glucose $25 \mathrm{ml}$ intravenously, preferably by catheter and not into a small distal vein.

(5) If alcohol is likely to be a factor give thiamine $100 \mathrm{mg}$ intravenously. If alcohol withdrawal is the cause give chlormethiazole (see (7)).

(6) Phenytoin (250 $\mathrm{mg}$ in $5 \mathrm{ml}$ ) intravenously 15 $\mathrm{mg} / \mathrm{kg}$ no faster than $50 \mathrm{mg} / \mathrm{min}$ by infusion pump or slow intravenous injection. (See note 2.)

Do not leave the patient until seizures have stopped.

If fits continue transfer the patient to the intensive care unit and consult an anaesthetist and a neurologist.

(7) Chlormethiazole $(8 \mathrm{mg} / \mathrm{ml})$ intravenously. Give a loading dose of up to $800 \mathrm{mg}(100 \mathrm{ml})$ over 10 minutes $(10 \mathrm{ml} / \mathrm{min})$, and maintain with $0 \cdot 5-1 \cdot 0$ $\mathrm{ml} / \mathrm{min}(4-8 \mathrm{mg})$.

Department of Neurolog Guy's Hospital, London SE1 5RT

M D O'Brien, FRCP, physician for nervous diseases

BrMed f 1990;301:918 mins. Then give thiopentone $1-3 \mathrm{mg} / \mathrm{kg} / \mathrm{h}$, maintaining a maximum blood thiopentone concentration of $60-100 \mathrm{mg} / \mathrm{l}$. (See note 3.)

A brain function monitor may be useful in determining whether there is seizure activity and the depth of barbiturate anaesthesia.

Notes

(1) Diazemuls is preferred because ordinary diazepam causes phlebitis. A bolus injection of $10 \mathrm{mg}$ may cause respiratory depression and hypotension, which may be pronounced if there is concurrent use of other central nervous system depressant drugs, especially phenobarbitone.

Diazepam must not be given intramuscularly or subcutaneously, added to an intravenous infusion, or given with phenobarbitone unless artificial ventilation is available.

Rectal diazepam (Stesolid rectal tubes), $5 \mathrm{mg}$ or $10 \mathrm{mg}$ in $2.5 \mathrm{ml}$, may be used for the immediate treatment of epilepsy instead of intravenous diazepam.

(2) Phenytoin must not be given intramuscularly or subcutaneously, given by central line, added to a dextrose infusion, or given with any other drug.

Intravenous phenytoin should be monitored with continuous electro-cardiography. If this is not available, it may be safer to use a dilute solution of $250 \mathrm{mg}$ ( $5 \mathrm{ml}$ ) of phenytoin in $250 \mathrm{ml}$ of physiological saline. The dilute solution should be used immediately provided that there is no evidence of precipitation and preferably with an in line filter (dilution of phenytoin is not licenced).

(3) Facilities for measuring blood thiopentone and pentobarbitone concentrations are available in only a limited number of centres, but it is still worth monitoring these concentrations if the patient requires continued treatment with thiopentone over several days. 